\title{
Erratum to: Is the modified Mallampati test performed in supine position a reliable predictor of difficult tracheal intubation?
}

\author{
Ashish Bindra $\cdot$ Hemanshu Prabhakar • \\ Gyaninder Pal Singh · Zulfiqar Ali • \\ Vasudha Singhal
}

Published online: 28 December 2010

(C) Japanese Society of Anesthesiologists 2010

Erratum to: J Anesth (2010) 24:482-485

\section{DOI 10.1007/s00540-010-0905-6}

The Editors regret that the original version of Table 2 of this article contained errors in the data. The corrected table is shown here. For details, see Comment on the original version (doi:10.1007/s00540-010-1039-6) and In reply to the comment (doi:10.1007/s00540-010-1040-0) as Letters to the Editor.
Table 2 Statistical terms used for modified Mallampati test (MMT) performed in sitting and supine positions as predicting tests for difficult laryngoscopy (number or \%)

\begin{tabular}{lrrrrrrrl}
\hline Test & TP & FP & TN & FN & $\begin{array}{l}\text { Se } \\
(\%)\end{array}$ & $\begin{array}{l}\text { Sp } \\
(\%)\end{array}$ & $\begin{array}{l}\text { PPV } \\
(\%)\end{array}$ & $\begin{array}{l}\text { NPV } \\
(\%)\end{array}$ \\
\hline MMT-sitting & 5 & 17 & 90 & 11 & 31 & 84 & 23 & 89 \\
MMT-supine & 11 & 42 & 65 & 5 & 69 & 61 & 21 & 93 \\
\hline
\end{tabular}

$M M T$ modified Mallampati test, $T P$ true positive, $F P$ false positive, $T N$ true negative, $F N$ false negative, $S e$ sensitivity, $S p$ specificity, $P P V$ positive predictive value, $N P V$ negative predictive value

The online version of the original article can be found under doi:10.1007/s00540-010-0905-6.

\begin{abstract}
A. Bindra $\cdot$ H. Prabhakar $(\bowtie) \cdot$ G. P. Singh $\cdot$ V. Singhal Department of Neuroanesthesiology, Neurosciences Centre, All India Institute of Medical Sciences, New Delhi 110029, India e-mail: prabhakarhemanshu@rediffmail.com
\end{abstract}

Z. Ali

Department of Anesthesiology,

Sher-i-Kashmir Institute of Medical Sciences, Srinagar, India 